University of Nebraska - Lincoln

DigitalCommons@University of Nebraska - Lincoln

U.S. Department of Veterans Affairs Staff

Publications

U.S. Department of Veterans Affairs

2011

\title{
The Alcohol Relapse Situation Appraisal Questionnaire: Development and Validation
}

Rosemarie A. Martin

Brown University, Rosemarie_Martin@Brown.Edu

Selene M. MacKinnon

Brown University, selene_mackinnon@brown.edu

Jennifer E. Johnson

Brown University, Jennifer_Johnson@brown.edu

Mark G. Myers

University of California - San Diego, mgmyers@ucsd.edu

Travis A.R. Cook

Providence VA Medical Center, Travis_Cook@brown.edu

See next page for additional authors

Follow this and additional works at: https://digitalcommons.unl.edu/veterans

Martin, Rosemarie A.; MacKinnon, Selene M.; Johnson, Jennifer E.; Myers, Mark G.; Cook, Travis A.R.; and Rohsenow, Damaris J., "The Alcohol Relapse Situation Appraisal Questionnaire: Development and Validation" (2011). U.S. Department of Veterans Affairs Staff Publications. 54.

https://digitalcommons.unl.edu/veterans/54

This Article is brought to you for free and open access by the U.S. Department of Veterans Affairs at DigitalCommons@University of Nebraska - Lincoln. It has been accepted for inclusion in U.S. Department of Veterans Affairs Staff Publications by an authorized administrator of DigitalCommons@University of Nebraska - Lincoln. 


\section{Authors}

Rosemarie A. Martin, Selene M. MacKinnon, Jennifer E. Johnson, Mark G. Myers, Travis A.R. Cook, and Damaris J. Rohsenow 


\title{
The Alcohol Relapse Situation Appraisal Questionnaire: Development and Validation
}

\author{
Rosemarie A. Martin ${ }^{\mathrm{a}, *}$, Selene M. MacKinnon ${ }^{\mathrm{a}}$, Jennifer E. Johnson ${ }^{\mathrm{c}}$, \\ Mark G. Myers ${ }^{\mathrm{d}}$, Travis A.R. Cook ${ }^{\mathrm{b}, \mathrm{a}}$, Damaris J. Rohsenow ${ }^{\mathrm{b}, \mathrm{a}}$ \\ a Center for Alcohol and Addiction Studies, Brown University, Providence, RI 02912, United States \\ b Providence VA Medical Center, 830 Chalkstone Ave., Providence, RI 02908, United States \\ ${ }^{\mathrm{c}}$ Department of Psychiatry and Human Behavior, Brown University, Providence, RI 02912, United States \\ d Psychology Service, Veteran Affairs San Diego Healthcare System and Department of Psychiatry, University of California, San Diego, CA 92161, United States
}

\section{A R T I C L E I N F O}

\section{Article history:}

Received 2 August 2010

Received in revised form 11 November 2010

Accepted 15 November 2010

Available online 14 January 2011

\section{Keywords:}

Alcohol

Relapse prevention

Appraisal

Coping

\begin{abstract}
A B S T R A C T
Background: The role of cognitive appraisal of the threat of alcohol relapse has received little attention. A previous instrument, the Relapse Situation Appraisal Questionnaire (RSAQ), was developed to assess cocaine users' primary appraisal of the threat of situations posing a high risk for cocaine relapse. The purpose of the present study was to modify the RSAQ in order to measure primary appraisal in situations involving a high risk for alcohol relapse.

Methods: The development and psychometric properties of this instrument, the Alcohol Relapse Situation Appraisal Questionnaire (A-RSAQ), were examined with two samples of abstinent adults with alcohol abuse or dependence. Factor structure and validity were examined in Study $1(N=104)$. Confirmation of the factor structure and predictive validity was assessed in Study $2(N=159)$.

Results: Results demonstrated construct, discriminant and predictive validity and reliability of the ARSAQ.

Discussion: Results support the important role of primary appraisal of degree of risk in alcohol relapse situations.
\end{abstract}

(c) 2011 Elsevier Ireland Ltd. All rights reserved.

\section{Introduction}

Coping with high-risk situations is an integral component of social learning theory formulations of alcohol abuse, and of cognitive-behavioral treatment (CBT) for alcohol abuse (Abrams and Niaura, 1987). Adequate coping skills are considered necessary for achieving and maintaining abstinence (Marlatt and Gordon, 1980) and represent the foundation for the development of relapse prevention and coping skills treatments (e.g., Chaney et al., 1978; Monti et al., 2002). Approaches that teach skills to cope with high-risk situations have demonstrated effectiveness in reducing post-treatment alcohol use (Chaney et al., 1978; Ferrell and Galassi, 1981; Greenwald et al., 1980; Monti et al., 1990; Rohsenow et al., 2001).

The types of situations in which most relapses occur for adults have been identified across addictive behaviors (Marlatt and Gordon, 1980; Marlatt, 1985; Shiffman, 1982). The most frequent

\footnotetext{
* Corresponding author at: Center for Alcohol \& Addiction Studies, Brown University, Box G-S121-5, Providence, RI 02912, United States. Tel.: +1 401863 6656; fax: +1 4018636697 .

E-mail address: Rosemarie_Martin@brown.edu (R.A. Martin).
}

relapse precipitants are negative emotional states, followed by social pressure to use, interpersonal conflict, urges and temptations to use (commonly with alcohol available), positive interpersonal emotional states, testing personal control, positive intrapersonal emotional states, and negative physical states. However, studies have found that it is the failure to use coping skills when high-risk situations are encountered, rather than the frequency of occurrence of high-risk situations per se, that most strongly predicts relapse (Miller et al., 1996). Since exposure to alcohol cues, negative affect, and many other high-risk situations is inevitable, effective use of coping skills when high-risk situations are encountered is essential.

When individuals have learned coping skills, effective use of coping skills also depends on an accurate appraisal of the riskiness of the situation (Abrams and Niaura, 1987). If the potential relapse situation is not perceived as dangerous, coping skills will not be initiated. Cognitive appraisal of the level of risk that a given situation presents has received little attention in the addictive behaviors literature. The two studies on this topic have shown that inadequate appraisal of relapse risk is related to poorer outcome for adult cocaine users (Myers et al., 1996) and adolescent substance abusers (Myers and Brown, 1990).

The concept of risk appraisal is based on the model of stress coping (Folkman and Lazarus, 1980; Lazarus and Folkman, 1984) 
which proposes that three types of appraisal are involved with stress coping. Primary appraisal involves assessing the level of stress or danger of a situation in terms of its potential negative consequences. Reappraisal involves a reassessment of the threat of the situation based on feedback or new information. Secondary appraisal involves assessing the adequacy of one's coping resources for handling the situation. Coping strategies are implemented when primary appraisal or reappraisal indicates that the situation is threatening and when secondary appraisal indicates adequate coping resources for the situation are available. Inaccurately appraising risky situations as non-threatening would increase the risk of relapse for those with alcohol use disorders. Thus, a way to assess primary appraisal of alcohol relapse risk situations is needed.

The cocaine Relapse Situation Appraisal Questionnaire (RSAQ; Myers et al., 1996) was developed to assess abstinent cocaine abusers' primary appraisal of the level of risk presented by cocaine high-risk situations (i.e., primary appraisal). Two hypothetical cocaine high-risk situations (one involving negative affect and one involving positive affect with social pressure) were chosen from the Cocaine-Specific Skills Test (CSST; Monti et al., 1997). Individuals in treatment for cocaine dependence rated various domains of cognitive appraisal of threat for each situation. A single component accounted for the responses to each situation, with high internal consistency, and for which construct, concurrent, predictive, and discriminant validity were demonstrated.

The purpose of the present study was to describe the development and psychometric properties of the Alcohol Relapse Situation Appraisal Questionnaire (A-RSAQ), an instrument modeled after the cocaine RSAQ and designed to assess primary appraisal of threat in alcohol relapse risk situations. In Study 1, the factor structure, internal consistency and test-retest reliability were investigated, followed by correlational analyses of construct, criterion-related, convergent and discriminant validity. In Study 2, we conducted factor analyses to confirm the factor structure and investigated predictive validity using a hierarchical regression model. We hypothesized that higher A-RSAQ scores would positively correlate with self-reported likelihood of drinking in the chosen situations (construct validity), with problem-focused and emotion-focused coping strategies (construct validity), with length of abstinence (criterion-related validity), with lifetime alcohol-related negative consequences (convergent validity), and with lower drinking rates during follow-up (predictive validity).

\section{Study 1: Development of the A-RSAQ}

\subsection{Methods}

2.1.1. Participants. The sample consisted of 104 adult male and female abstinent alcohol abusers drawn from the community via newspaper advertisements. The purpose of the study was described in the advertisement as a study investigating coping and sobriety, and targeted those who had experienced negative consequences from their alcohol use and who no longer drink. Eligible participants had a lifetime diagnosis of alcohol abuse or alcohol dependence according to the alcohol use disorders section of the Structured Clinical Interview for DSM-IV (SCID-IV; First et al., 1995), were 18 years of age or older, and no longer drank alcohol. In order to obtain a sample with a wide range of abstinence, no minimum or maximum requirements for duration of current abstinence were set. Participants were paid $\$ 25$ for completion of the initial assessments and $\$ 10$ for completion of the retest. The research procedures were approved by the Institutional Review Board of Brown University.

Participants ranged in age from 18 to 86 years $(M=45.7, S D=14.4)$ and $57(55 \%)$ were men and 47 (45\%) were women. The majority of participants (94\%) were White, $3 \%$ were Black, and $3 \%$ were of other races. The average education of the sample was 14.3 years $(S D=2.8$, range $=8-23$ years $)$. Using the SCID-IV, $102(98 \%)$ met lifetime diagnostic criteria for alcohol dependence, and 2 (2\%) for alcohol abuse. The sample had an average of 5.9 years $(S D=6.9$; range $=1$ day to 27 years; $M d n=3.01$ years $)$ of abstinence at the time of the assessment.

2.1.2. Procedure. Participants completed all instruments during an initial interview. In order for the stability of the A-RSAQ across time to be evaluated, 91 participants (88\%) returned one week after the completion of their first assessment session to complete the A-RSAQ a second time, completing it a mean of 8.3 days later $(S D=2.9)$.

2.1.3. Instruments. A-RSAQ. The A-RSAQ is a self-report instrument consisting of two hypothetical alcohol relapse risk situations (one negative affect and one positive affect in a social situation) and 26 appraisal items, identical for each situation. Given the number of appraisal items, two situations were chosen to be appraised, as representative situations. The choice of situations was derived by content analysis of unpublished relapse situation data gathered in previous studies using the Conditions Surrounding Relapse Interview (Monti et al., 2001; Rohsenow et al., 2001), in which respondents described situations in which they relapsed during a 6-month follow-up time period. The coding analysis of the Conditions Surrounding Relapse data identified both negative and positive moods as being most strongly associated with urge or relapse situations, with depressed mood and social positive affect situations the most common content. This finding is consistent with the alcohol relapse literature (Marlatt, 1985; Zywiak et al., 1996) and consistent with the high-risk situations used in the cocaine RSAQ. In addition to domains of affect and social presence, the presence of alcohol differed since negative affect situations generally did not include alcohol cues while positive affect social situations were commonly in the presence of alcohol beverages. The content of the two A-RSAQ relapse risk situations was taken from published instruments that contained situations that were representative of depressed mood and social positive situations and that could occur to almost any alcoholic. The content of the negative affect situation was drawn from the Coping with Alcohol-Related Situations instrument (CARS; Rohsenow et al., 2001) and read as follows: "You feel lonely and worthless. No one seems to need you or care about you anymore." The content of the positive affect situation (social positive situation with alcohol cues) was drawn from the Situational Competency Test (SCT Chaney et al., 1978) and read as follows: "You are eating at a good restaurant on a special occasion with some friends. The waitress comes over and says, 'Drink before dinner?' Everyone else orders one. All eyes seem to be on you."

Participants were presented with one of the situations at a time. After reading the first A-RSAQ situation participants were asked to rate the likelihood of not using alcohol (mixture of primary and secondary appraisal) in the situation presented using a 7-point Likert scale ranging from "definitely will use" (1) to "definitely won't use" (7). This item was included for use in validating the A-RSAQ situations. Participants were next instructed to rate each of the 26 risk appraisal items as to the extent to which they agreed with the item on 7-point Likert scales ranging from "not at all" (1) to "very much so" (7). The appraisal items (see Table 1) were selected to represent various domains of threat or harm, including personal well-being, wellbeing of significant others, and self-esteem, and are the same appraisal items used in the cocaine RSAQ (Myers et al., 1996). Thus, the instructions were intended to elicit primary appraisal of risk for relapse based on features of the hypothetical situation. These procedures were repeated for the second situation, with order of administration of the two situations counterbalanced.

Revised Ways of Coping Checklist (RWCCL). The RWCCL (Vitaliano et al., 1985) is a self-report instrument designed to assess the use of both problem-focused and emotion-focused coping strategies in stressful situations. The RWCCL consists of a self-identified stressful situation, appraisal items, and a checklist of coping items. The RWCCL was used in the present study in order to examine the construct validity of the A-RSAQ as higher appraised risk will lead to more use of coping strategies. For the purposes of the present study, participants were presented with the same two hypothetical situations used for the A-RSAQ (as described earlier) and then asked to respond to 27 coping items. As with the cocaine RSAQ (Myers et al., 1996), a subset of 27 of the 57 items of the RWCCL that reflect cognitive coping strategies was used, and data analysis included only the 21 items identified in the most recent factor analysis of the RWCCL (Vitaliano, 1993). These were drawn from the following four subscales of the RWCCL: Count Your Blessings ( 6 items), Blamed Self ( 3 items), Wishful Thinking ( 8 items), and Avoidance (4 items). For each RWCCL item, participants answer the question "How likely is it that you would do or think any of the following" on a 7-point Likert scale from (1) "definitely not" to (7) "definitely would". A coping scale score was computed for each of the two situations by summing the item scores. The RWCCL coping scales have been shown to have good reliability and validity (Vitaliano, 1993).

Lifetime Drinking History $(L D H)$. The LDH (Skinner and Sheu, 1982) is a structured, interviewer-administered instrument for gathering drinking pattern information beginning with the onset of regular drinking. The LDH has been shown to be a reliable (Skinner and Sheu, 1982) and valid (Skinner, 1982) instrument. Only the duration of the current episode of abstinence prior to the date of assessment was used from this measure.

Drinker Inventory of Consequences (DrInC). The DrInC (Miller et al., 1995) is a 50 -item, self-administered instrument with a true/false response format. The DrInC is designed to assess alcohol-related negative consequences in five domains: interpersonal, intrapersonal, physical, social, and impulsive. The DrInC was used in the present study to assess lifetime severity of alcohol problems to establish convergent validity. Excellent criterion and construct validity and reliability have been established for the lifetime version (Miller et al., 1995).

Demographics questionnaire. A demographics questionnaire assessed age, gender, ethnicity, education, and employment status.

Structured Clinical Interview for DSM-IV alcohol use disorders section (SCID-IV; First et al., 1995). The SCID-IV was used for screening purposes in both samples. 
Table 1

Principal-components analysis component solution for the Alcohol Relapse Situation Appraisal Questionnaire (A-RSAQ): items and component loadings.

\begin{tabular}{|c|c|c|c|c|}
\hline \multirow[t]{2}{*}{ A-RSAQ item } & \multicolumn{2}{|l|}{ Study 1} & \multicolumn{2}{|l|}{ Study 2} \\
\hline & $\begin{array}{l}\text { Negative affect } \\
\text { loading }\end{array}$ & $\begin{array}{l}\text { Social positive } \\
\text { affect loading }\end{array}$ & $\begin{array}{l}\text { Negative affect } \\
\text { loading }\end{array}$ & $\begin{array}{l}\text { Social positive } \\
\text { affect loading }\end{array}$ \\
\hline Is this situation one where you might fail? & .81 & .85 & .79 & .75 \\
\hline Is this situation one where you might let yourself down? & .79 & .84 & .78 & .76 \\
\hline Is this situation one that affects your whole life? & .79 & .85 & .76 & .71 \\
\hline Is this situation one which is very threatening? & .79 & .85 & .77 & .70 \\
\hline Is this situation one in which you might appear incompetent? & .77 & .83 & .74 & .69 \\
\hline Is this situation one in which you might become very anxious? & .77 & .84 & .75 & .72 \\
\hline $\begin{array}{l}\text { Is this situation one that could cause harm to your own health, safety, or physical } \\
\text { well-being? }\end{array}$ & .75 & .87 & .80 & .63 \\
\hline Is this situation one that could lead to depression? & .75 & .91 & .82 & .70 \\
\hline $\begin{array}{l}\text { Is this situation one where you might lose the approval or respect of someone important to } \\
\text { you? }\end{array}$ & .75 & .89 & .86 & .76 \\
\hline Is this situation one in which you might feel frustrated? & .74 & .83 & .79 & .73 \\
\hline Is this situation one where you might lose self-respect? & .74 & .84 & .87 & .76 \\
\hline Is this situation one for which someone else might come down on you? & .73 & .87 & .79 & .68 \\
\hline Is this situation one in which you might be upset with someone else? & .71 & .74 & .73 & .69 \\
\hline Is this situation one which will require major sacrifices? & .70 & .83 & .76 & .60 \\
\hline Is this situation one that could lead to a strain on your financial resources? & .70 & .82 & .72 & .58 \\
\hline Is this situation one that you are afraid of confronting? & .70 & .76 & .79 & .68 \\
\hline Is this situation one in which you could appear to be an uncaring person? & .70 & .82 & .80 & .67 \\
\hline Is this situation one where someone else might annoy or aggravate you? & .69 & .71 & .75 & .67 \\
\hline Is this situation one you think about often? & .69 & .82 & .75 & .68 \\
\hline Is this situation one where you might look like a jerk? & .66 & .77 & .76 & .66 \\
\hline $\begin{array}{l}\text { Is this situation one which might result in not achieving an important goal at your job or } \\
\text { work? }\end{array}$ & .64 & .76 & .56 & .53 \\
\hline $\begin{array}{l}\text { Is this situation one which could result in a loved one having difficulty getting along in the } \\
\text { world? }\end{array}$ & .64 & .78 & .77 & .63 \\
\hline Is this situation one where you could be victimized? & .64 & .68 & .75 & .59 \\
\hline Is this situation one which might lead to legal problems? & .63 & .78 & .75 & .59 \\
\hline Is this situation one that could cause harm to a loved one's emotional well-being? & .59 & .83 & .79 & .62 \\
\hline Is this situation one that is very important to you? & .56 & .73 & .69 & .56 \\
\hline
\end{tabular}

2.1.4. Data analysis approach. Principal components analyses (PCAs) were conducted separately on appraisal items for each of the two A-RSAQ relapse risk situations. Responses to only the first administration of the instrument were used in the PCA. Responses to the second administration of the instrument were used for test-retest reliability analysis only. The number of components retained was determined using: scree test (Cattell, 1966) and parallel analysis (Horn, 1965). Parallel analysis has been found to be one of the most consistently accurate methods of PCA (Zwick and Velicer, 1986).

Partial correlations between appraisal scores and all validation variables were conducted in order to control for the effect of the other appraisal score. Appraisal scores from the two administration orders of the A-RSAQ were combined since no administration order effects were found. Construct validity was assessed by examining the correlations between appraisal scores and the coping scales of the RWCCL and ratings of perceived likelihood of drinking in each of the situations. Based on stress coping model, we hypothesized that higher A-RSAQ appraisal scores would be positively correlated with greater perceived likelihood of drinking, as well as with more use of all four RWCCL coping categories. Criterionrelated validity was assessed by examining the correlations between appraisal scores and length in days of the period of abstinence preceeding the day of first assessment. We hypothesized that higher A-RSAQ appraisal scores would be negatively correlated with length of abstinence. Convergent validity was assessed using correlations with number of lifetime alcohol-related negative consequences as measured by total scores on the DrInC. Discriminant validity was assessed by examining the correlations of negative and positive appraisal scores with age and education since these would not be expected to correlate with appraisal scores.

\subsection{Results}

2.2.1. Factor structure. The PCA results found that the scree test and parallel analysis produced the same result, so the one-component solution for each situation was retained. All items loaded .40 or greater on the component and so were retained. The component accounted for a substantial proportion of total item variance in both the negative affect and social positive affect situations (50.6\% and $66.2 \%$, respectively). The items and their component loadings are presented in Table 1.
2.2.2. Reliability. An appraisal score was derived for each situation by summing the 26 items for each situation, with possible scores ranging from 26 to 182 . The negative affect situation total appraisal score ranged from 26 to $182(M=97.9$; $S D=37.5)$, and the social positive affect situation total appraisal score ranged from 26 to $173(M=69.2 ; S D=44.7)$. Both the negative and social positive affect appraisal scales yielded high internal consistency coefficients (Cronbach's $\alpha=.96$ and $\alpha=.98$, respectively), and were significantly, but not highly, intercorrelated $(r=.36, p<.001 ; 13 \%$ shared variance). The test-retest correlation coefficient for both the negative affect and social positive affect scenes was significant at the $p<.001$ level ( $r=.71$ and $r=.63$, respectively). No differences for the presentation order of scenes were found in paired $t$-tests.

2.2.3. Validation analyses. Construct validity. Table 2 displays the mean and standard deviation of the validation variables, as well as bivariate and partial correlations ( $p r)$ between situation appraisal scores and validation variables. As seen in Table 2 , all but one of the RWCCL coping scale scores were significantly correlated with ARSAQ appraisal scores for both scenes, even after controlling for the appraisal of one situation in appraisal of the other situation. Only the RWCCL Count Your Blessings scale score was not significantly correlated with the appraisal score for either situation. Likelihood of drinking was reverse-scored so that high scores would mean high likelihood of drinking for ease of interpretability. The likelihood of drinking in response to the social positive affect scene was logtransformed to correct for skewness. As seen in Table 2, all of these correlations are significant, indicating greater likelihood of drinking with a greater perceived overall threat of the situation.

Criterion-related validity. The social positive affect appraisal scores were significantly and negatively correlated with length of current episode of abstinence, indicating a lower perceived threat of the situation the longer the period of abstinence preceding the 
Table 2

Correlations of A-RSAQ scale appraisal scores with validation variables.

\begin{tabular}{|c|c|c|c|c|c|}
\hline \multirow[t]{2}{*}{ Validation measure } & \multirow[t]{2}{*}{$M(S D)$} & \multicolumn{2}{|c|}{$\begin{array}{l}\text { Negative affect scene appraisal } \\
\text { score }\end{array}$} & \multicolumn{2}{|c|}{$\begin{array}{l}\text { Social positive affect scene } \\
\text { appraisal score }\end{array}$} \\
\hline & & $r$ & $p r$ & $r$ & $p r$ \\
\hline \multicolumn{6}{|l|}{ Construct validity ${ }^{\mathrm{a}}$} \\
\hline \multicolumn{6}{|c|}{ Coping scale - negative affect scene } \\
\hline Count Your Blessings & $28.0(9.0)$ & .07 & .05 & - & - \\
\hline Wishful Thinking & $33.4(11.1)$ & $.61^{* * *}$ & $.54^{* * *}$ & - & - \\
\hline Blamed Self & $12.1(5.2)$ & $.47^{* * *}$ & $.35^{* * *}$ & - & - \\
\hline Avoidance & $13.4(5.0)$ & $.38^{* * *}$ & $.37^{* * *}$ & - & - \\
\hline \multicolumn{6}{|c|}{ Coping scale - positive affect scene } \\
\hline Count Your Blessings & 25.5(9.9) & - & - & $.23^{*}$ & .17 \\
\hline Wishful Thinking & $19.9(12.3)$ & - & - & $.67^{* * *}$ & $.60^{* * *}$ \\
\hline Blamed Self & $7.5(5.0)$ & - & - & $.70^{* * *}$ & $.61^{* * *}$ \\
\hline Avoidance & $12.1(4.7)$ & - & - & $.42^{* * *}$ & $.28^{* *}$ \\
\hline Likelihood of drinking ${ }^{\mathrm{b}}$ & $.45^{* * *}$ & $.35^{* * *}$ & $.43^{* * *}, \mathrm{c}$ & $.37^{* * *}$ & \\
\hline Negative affect scene & $2.13(1.52)$ & - & - & - & - \\
\hline Positive affect scene & $1.60(1.22)$ & - & - & - & - \\
\hline \multicolumn{6}{|l|}{ Criterion-related validity ${ }^{\mathrm{a}}$} \\
\hline Length of current abstinence & 5.9(6.9) years & $-.25^{*}$ & -.11 & $-.41^{* * *}$ & $-.35^{* * *}$ \\
\hline \multicolumn{6}{|l|}{ Convergent validity ${ }^{\mathrm{a}}$} \\
\hline DrInC total & $37.2(8.3)$ & .07 & .02 & .17 & .18 \\
\hline \multicolumn{6}{|l|}{ Discriminant validity ${ }^{\mathrm{a}}$} \\
\hline Age & $45.7(14.4)$ & $-.19^{*}$ & -.02 & $-.30^{* *}$ & -.09 \\
\hline Education & $14.3(2.8)$ & $-.23^{*}$ & -.04 & $-.42^{* * *}$ & $-.27^{* *}$ \\
\hline
\end{tabular}

a Partial correlations control for the other appraisal scene score.

b Variable was reverse-coded for interpretability.

c Variable was log-transformed to correct for skewness.

${ }^{*} p \leq .05$.

** $p \leq .01$.

$p \leq .001$.

assessment. The bivariate relationship between the negative affect appraisal scores and length of current period of abstinence was significant, but was not significant after controlling for variance due to the social positive affect scale score.

Convergent validity. The mean number of lifetime alcoholrelated negative consequences on the DrInC was in the high range, with no significant gender differences. The DrInC total score was not significantly correlated with either the negative or positive appraisal score.

Discriminant validity. Age and education were not significantly correlated with the negative appraisal score but were correlated with the social positive appraisal score (see Table 2 ).

\section{Study 2: Confirmation of the A-RSAQ factor structure and predictive validity}

\subsection{Methods}

3.1.1. Participants. Participants were drawn from a larger study examining predictors of relapse. They were recruited from an urban treatment center when entering outpatient treatment after completing residential or day treatment programs. Alcohol was not necessarily the substance for which patients were seeking treatment, but all participants met DSM-IV diagnostic criteria for an alcohol use disorder during the past year. Individuals with an active diagnosis of psychosis or organic brain impairment were excluded. Participants were contacted for follow-up at 3 and 6 months after the baseline assessment. Participants were paid $\$ 30$ for completing the in-person baseline assessment and $\$ 35$ and $\$ 40$ for completing the in-person 3 and 6 month follow-up assessments. The research procedures were approved by the Institutional Review Board of Brown University.

The sample consisted of $74(47 \%)$ men and 85 (53\%) women. Participants ranged in age from 18.9 to 59.2 years $(M=36.9, S D=8.6)$. The majority of participants (76\%) were White, $19 \%$ were Black, and $5 \%$ were of other races, consistent with the demographics of Rhode Island where this study was conducted. The average education of the sample was 12 years ( $S D=2.1$, range $=7-18$ years). Using the SCID-IV, 158 (98\%) met lifetime diagnostic criteria for alcohol dependence, and $3(2 \%)$ for alcohol abuse. The sample had an average of 23.1 days $(S D=26.3$; range $=1-145$ days; $\mathrm{Mdn}=15$ days ) of abstinence from alcohol at the time of the assessment.

3.1.2. Procedure. Participants completed the baseline assessments within two weeks of entering outpatient treatment. Most $(N=124 ; 78 \%)$ were interviewed at the 6 -month follow-up. At 6 -months, $48 \%$ of the follow-up sample $(N=59)$ had drunk alcohol; among these, the mean percentage of drinking days was $14.3(S D=24.0)$ and mean percentage of heavy drinking days was $11.1(S D=22.1)$.

3.1.3. Instruments. As in Study 1, participants completed the A-RSAQ for each situation. The order of administration of the two situations was counterbalanced to control for possible order effects. Participants also completed the demographics questionnaire and SCID as in Study 1.

Timeline Followback. The Timeline Followback (TLFB; Sobell and Sobell, 1995) interview administered at pretreatment (for the 90 days prior to baseline assessment) and at follow-up collected data on quantity of alcohol used each day. At follow-up, a family member or close friend (significant other; S.O.) was interviewed about the participant's alcohol use, used as a bogus pipeline. Procedures increasing the validity of self-report (Sobell and Sobell, 1986) were followed. Percentage of drinking days, percentage of heavy drinking days, and average drinks per drinking day at baseline and follow-up were calculated from TLFB.

3.1.4. Data analysis approach. To confirm the factor structure found in Study 1, PCAs were conducted on responses from Study 2 using the same methods as Study 1 . Predictive validity was assessed by examining relationships between appraisal scores and the drinking variables during the 6 month follow-up. Hierarchical multiple regressions were used to assess whether the relationship between appraisal and each follow-up alcohol use variable was independent of pretreatment alcohol use. The corresponding alcohol use variable from the baseline assessment was entered on step one and the appraisal score was entered on step two.

\subsection{Results}

3.2.1. Factor structure. Scree test and parallel analysis retained one component for each situation. All items loaded 40 or greater on the component. The component accounted for $45.2 \%$ and $59.2 \%$ of total item variance in both the negative affect and social positive affect situations, respectively. The items and their component loadings are presented in Table 1.

3.2.2. Reliability. An appraisal score was derived for each situation by summing the 26 items for each situation, with possible scores ranging from 26 to 182 . The mean negative affect situation total appraisal score was $107.41(S D=42.89)$, and the social positive affect situation total appraisal score was 126.13 $(S D=31.27)$. Both the negative and social positive affect appraisal 
scales yielded high internal consistency coefficients (Cronbach's $\alpha=.95$ and $\alpha=.97$, respectively), and were significantly intercorrelated ( $r=.69, p<.001 ; 48 \%$ shared variance).

3.2.3. Predictive validity. The social positive situation appraisal score significantly predicted percentage of drinking days, even after the influence of pretreatment drinking had been considered, $\left(s r^{2}=-.22, \beta=-.22, F_{\text {change }}(1,121)=6.09, p<.05\right)$. The social positive situation appraisal score significantly predicted the average number of drinks per drinking day, even after the influence of pretreatment drinking had been considered, $\left(s r^{2}=-.24, \beta=-.20\right.$, $\left.F_{\text {change }}(1,70)=4.27, p<.05\right)$. The negative situation appraisal score significantly predicted percentage of heavy drinking days, even after the influence of pretreatment drinking had been considered, $\left(s r^{2}=-.24, \beta=-.24, F_{\text {change }}(1,121)=7.23, p<.01\right)$. Thus, perceiving greater threat in these situations predicted lower drinking rates during follow-up.

\section{Discussion}

The aim of the present studies was to examine the factor structure and psychometric properties of the A-RSAQ a measure of primary appraisal (i.e., appraisal of general threat) of two common alcohol relapse risk situations. The findings from this study support a unitary factor structure, internal consistency, stability, and validity for each scale of the A-RSAQ. The component pattern for both samples is strong, and confirmation in a second sample strengthens the findings. Overall, the A-RSAQ appears to be a valid instrument for assessing threat appraisal presented by alcohol high-risk situations as perceived by abstinent alcohol abusers with the ability to predict post-treatment drinking. Specifically, the A-RSAQ had excellent internal consistency reliability; adequate test-retest reliability; excellent construct, predictive, and factorial validity; good criterion-related validity; and acceptable discriminant validity, but more information on convergent validity is needed.

Appraisal of each of the risk situations had exceptionally high internal consistency and excellent temporal stability. The ratings of the two relapse risk situations shared $13 \%$ of variance in the first study and $48 \%$ in the second study, indicating some degree of independence in the appraisal of negative and social positive affect situation. This is consistent with the idea that negative-affect and positive-affect based systems of motivation may involve different underlying systems (Baker et al., 1987). Thus, the ability of an abstinent alcohol abuser to recognize the danger in one type of situation will not necessarily predict his/her ability to recognize risk in another major type of situation, and the threat of relapse posed by different types of risky situations needs to be addressed separately in treatment. This may suggest that more high-risk situations need to be included in the instrument. However, given the length of the instrument with two situations, the fact that these two situations are problematic for almost all alcoholics, and the predictive validity provided by these two situations, the current version of the A-RSAQ may be sufficient for clinical purposes.

The validity of the A-RSAQ was demonstrated in several ways. First, construct validity was supported by significant relationships between appraisal scores for each situation and three of the four Revised Ways of Coping Checklist coping scales, even after controlling variance due to appraisal of the other situation. This supports the use of the A-RSAQ as a measure of threat appraisal because the greater the appraised threat, the greater the likelihood that a coping strategy will be used. The minimal correlation with the Count Your Blessings coping scale may indicate that this coping method is not commonly used as a means to remain abstinent in high-risk situations. Appraisal scores for both situations were also significantly correlated with self-rated likelihood of drinking in the situation, providing evidence that the situations are perceived as threats to abstinence. The results suggest that the measure may be useful within treatment to identify individuals who do not adequately recognize the degree of threat inherent in these two common relapse situations. Individuals with low scores on one or both scales may need to learn to more accurately appraise the riskiness of these situations to their sobriety lest they fail to initiate coping strategies when risky situations occur.

Second, criterion-related validity was tested by examining the relationship between appraisal scores and the length of abstinence immediately preceding the time of first assessment. The hypothesis was supported by bivariate correlations. The relationship between length of past abstinence and the rating of the negative affect situation was no longer significant when the variance shared with the social positive affect situation was controlled for. This may indicate that the social positive affect situation remains threatening to overall well-being even with extended periods of abstinence, or that the negative affect situation appraisal does not add significant additional variance above that accounted for by the appraisal of positive social situations.

Third, discriminant validity was supported by demonstrating low correlations between appraisal scores and age and education, and no significant correlations with age of respondents when controlling for the other appraisal score and length of abstinence. However, when controlling for negative affect situation appraisal and length of abstinence, education remained significantly and negatively correlated with social positive affect situation appraisal scores. It is likely that older and more educated people are better able to handle social pressure situations and therefore perceive this type of situation as less threatening.

Convergent validity was tested by examining the relationship between appraisal scores and number of alcohol-related negative consequences ever experienced via the DrInC. Neither appraisal score was significantly related to DrInC scores, indicating that the current overall perceived threat of these high-risk situations is not related to the number of alcohol problems experienced in one's lifetime. This finding might be due to the sample consisting of abstinent individuals. These consequences may have occurred at any time in the past. Situational appraisal is expected to predict increased future negative consequences due to increased drinking following appraisal in real life, not consequences preceding it. Also, alcohol problems are not good predictor of drinking outcomes (Adamson et al., 2009). This suggests good discrimination between measures of problems and perceived threat.

Predictive validity also was demonstrated by the measure's ability to predict drinking during the 6 months after treatment. Higher threat appraisal on the social positive situation predicted fewer drinking days and fewer drinks on days that they drank and for the negative affect situation predicted fewer heavy drinking days. While negative and social positive affect situations may pose particular risks for drinking, those who appraise negative or positive affect situations as more threatening or harmful may be better able to mobilize their coping resources to manage or avoid these situations without drinking or without drinking heavily.

These validation results of the A-RSAQ are consistent with validation results of the cocaine RSAQ (Myers et al., 1996). In both instruments, single-component solutions were found for each situation; both instruments were found to correlate with perceived relapse risk and with the coping scales, and the predictive validity of the cocaine RSAQ was supported for appraisal of the negative affect situation. Thus both instruments may have clinical utility in identifying individuals who need to learn to more accurately appraise the riskiness of situations in order to utilize coping skills.

Only one known scale is designed to assess relapse risk appraisal among adults treated for alcohol abuse. The Relapse Precipitants Inventory (RPI; Litman, 1986; Litman et al., 1977a,b) was developed 
to assess perceived level of "danger to staying off drink" that each of 25 situations presented. Total RPI scores and scores on two of the three factors were shown to correlate significantly with subsequent relapse, indicating that the greater the number of situations rated as dangerous, especially for mood states, external events, and euphoria, the more likely one was to have relapsed 6 or 15 months later. However, the number of dangerous situations is not conceptually the same as degree of threat seen in situations. RPI responses may represent the appraisal of ability to avoid drinking or self-efficacy and not the riskiness of the situation. Self-efficacy is predictive of drinking outcomes (Bandura, 1982; Burling et al., 1989; DiClemente et al., 1995). This may explain why RPI results differ from those obtained in this current study and in Myers et al. (1996), both of which found that the higher the risk appraisal, the fewer days on which alcohol or cocaine was used during follow-up. Results with the RSAQ and A-RSAQ are both consistent with theories of the role of cognitive appraisal of risk (Lazarus and Folkman, 1984).

In summary, the A-RSAQ is a psychometrically sound measure for assessing appraisal of threat posed by alcohol relapse-risk situations among abstinent adult alcohol abusers. The appraisal scores of the A-RSAQ correlate with relapse risk assessment for the situations presented, indicating that each situation presented a level of perceived relapse risk. The A-RSAQ is unique in that it is a measure of broad, general threat to individuals' well-being in two high-risk situations. Results of the present study support the findings of Myers et al. (1996) and provide additional support for the importance of appraisal of high-risk situations during abstinence. Clinically, these measures can be used to identify individuals who are not sufficiently aware of the degree of risk posed by common relapse situations.

One limitation of the present study is that the A-RSAQ was not validated against the only other known published alcohol relapse risk appraisal instrument, the RPI. However, since the RPI assesses number of risky situations rather than degree of risk appraisal, and since the RPI had limited validity data and used a statistical procedure that leads to sample-bound results, it is not clear that the RPI would be a better instrument for validation than the ones we used. A second limitation is that only two common high-risk situations were appraised, due to the length of assessment for each. It would be useful to determine whether adding several other situations would increase predictive validity without adding undue burden. Third, only sober community members and outpatients from one city were included. It would be useful to determine predictive validity in other populations and with alcoholics currently in residential treatment.

\section{Role of funding source}

Funding for this project was provided by grant R01AA12701 from the National Institute on Alcohol Abuse and Alcoholism, by T32 AA07459 from the National Institute on Alcohol Abuse and Alcoholism, by K23 DA021159 from the National Institute on Drug Abuse, by a Research Excellence Award from Brown University's Center for Alcohol and Addiction Studies, and by a Senior Career Scientist Award from the Department of Veterans Affairs. NIDA, NIAAA, and the VA had no further role in study design; in the collection, analysis and interpretation of data; in the writing or the report; or in the decision to submit the paper for publication.

\section{Contributors}

Authors Martin, MacKinnon, Rohsenow, and Cook designed the study. Authors Martin and MacKinnon wrote the protocol and undertook statistical analyses. Authors Myers, Johnson, and Cook completed literature searches and summaries of previous work.
Author Martin wrote the first draft of the manuscript. All authors contributed to and have approved the final manuscript.

\section{Conflict of interest}

Authors declare that they have no conflicts of interest.

\section{Acknowledgement}

An earlier draft of part of the results was presented at the annual meeting of the Research Society on Alcoholism, Santa Barbara, CA, June 2005.

\section{References}

Abrams, D.B., Niaura, R.S., 1987. Social learning theory. In: Blane, H., Leonard, K (Eds.), Psychological Theories of Drinking and Alcoholism. Guilford Press, New York.

Adamson, S.J., Sellman, J.D., Frampton, C.M.A., 2009. Patient predictors of alcohol treatment outcome: a systematic review. J. Subst. Abuse Treat. 36, 75-86.

Baker, T.B., Morse, E., Sherman, J.E., 1987. The motivation to use drugs: a psychobiological analysis of urges. In: Rivers, C. (Ed.), The Nebraska Symposium on Motivation: Alcohol Use and Abuse. University of Nebraska Press, Lincoln, NE, pp. 257-323.

Bandura, A., 1982. Self-efficacy mechanism in human agency. Am. Psychol. 37, 122-147.

Burling, T.A., Reilly, P.M., Moltzen, J.O., Ziff, D.C., 1989. Self-efficacy and relapse among inpatient drug and alcohol abusers: a predictor of outcome. J. Stud. Alcohol 50, 354-360.

Cattell, R.B., 1966. Handbook of Multivariate Experimental Psychology. Rand McNally, Chicago, IL.

Chaney, E.F., O'Leary, M.R., Marlatt, G.A., 1978. Skill training with alcoholics. J. Consult. Clin. Psychol. 46, 1092-1104.

DiClemente, C.C., Fairhurst, S.K., Piotrowski, N.A., 1995. Self efficacy and addictive behaviors. In: James, E., Maddux (Eds.), Self efficacy, Adaptation, and Adjustment: Theory, Research, and Application. Plenum Press, New York, pp. 109-141.

Ferrell, W.L., Galassi, J.P., 1981. Assertion training and human relations training in the treatment of chronic alcoholics. Int. J. Addict. 16, 959-968.

First, M.B., Spitzer, R.L., Gibbon, M., Williams, J., 1995. Structured Clinical Interview for DSM-IV Axis I Disorders-Non Patient Edition. Biometrics Research Department. Psychiatric Institute, New York.

Folkman, S., Lazarus, R.S., 1980. An analysis of coping in a middle aged community sample. J. Health Soc. Behav. 21, 219-239.

Greenwald, M.A., Kloss, J.P., Kovaleski, M.E., Greenwald, D.P., Twentyman, G.T. Zibung-Hoffman, P., 1980. Drink refusal and social skills training with hospitalized alcoholics. Addict. Behav. 5, 227-256.

Horn, J.L., 1965. A rationale and test for the number of factors in factor analysis. Psychometrika 30, 179-185.

Lazarus, R.S., Folkman, S., 1984. Stress Appraisal and Coping. Springer, New York.

Marlatt, G.A., 1985. Situational determinants of relapse and skill-training interventions. In: Marlatt, G.A., Gordon, J.R. (Eds.), Relapse Prevention. Guilford Press, New York, pp. 71-127.

Marlatt, G.A., Gordon, J.R., 1980. Determinants of relapse: implications for the maintenance of behavior change. In: Davidson, P.O., Davidson, S.M. (Eds.), Behavioral Medicine: Changing Health Lifestyles. Brunner/Mazel, New York.

Miller, W.R., Tonigan, J.S., Longabaugh, R., 1995. The Drinker Inventory of Consequences (DrInC): an instrument for assessing adverse consequences of alcoho abuse: test manual. Vol. 4: Project MATCH Monograph Series. NIH Pub. No. 95-3911. National Institute on Alcohol Abuse and Alcoholism, Washington, DC.

Miller, W.R., Westerberg, V.S., Harris, R.J., Tonigan, J.S., 1996. What predicts relapse? Prospective testing of antecedent models. Addiction 91, S155-S171.

Monti, P.M., Abrams, D.B., Binkoff, J.A., Zwick, W.R., Liepman, M.R., Nirenberg, T.D., Rohsenow, D.J., 1990. Communication skills training, communications skills training with family and cognitive behavioral mood management training for alcoholics. J. Stud. Alcohol 51, 263-270.

Monti, P.M., Kadden, R.M., Rohsenow, D.J., Cooney, N.L., Abrams, D.B., 2002. Treating Alcohol Dependence: A Coping Skills Training Guide. The Guilford Press, New York.

Monti, P.M., Rohsenow, D.J., Michalec, E., Martin, R.A., Abrams, D.B., 1997. Brief coping skills treatment for cocaine abuse: substance use outcomes at 3 months. Addiction 92, 1717-1728.

Monti, P.M., Rohsenow, D.J., Swift, R.M., Gulliver, S.B., Colby, S.M., Mueller, T.I. Brown, R.A., Gordon, A., Abrams, D.B., Niaura, R.S., Asher, M.K., 2001. Naltrexone and cue exposure with coping and communication skills training for alcoholics: treatment process and one-year outcomes. Alcohol. Clin. Exp. Res. 25, 1634-1647.

Myers, M.G., Brown, S.A., 1990. Coping and appraisal in relapse risk situations among adolescent substance abusers following treatment. J. Adolesc. Chem. Depend. 1 95-116.

Myers, M.G., Martin, R.A., Rohsenow, D.J., Monti, P.M., 1996. The Relapse Situation Appraisal Questionnaire: initial psychometric characteristics and validation. Psychol. Addict. Behav. 10, 237-247. 
Litman, G.K., 1986. Alcoholism survival: the prevention of relapse. In: Miller, W.R., Heather, N. (Eds.), Treating Addictive Behaviors: Processes of Change. Plenum Press, New York, pp. 391-405.

Litman, G.K., Eiser, J.R., Rawson, N.S.B., Oppenheim, A.N., 1977a. Towards a typology of relapse: a preliminary report. Drug Alcohol Depend. 2, 157-162.

Litman, G.K., Eiser, J.R., Rawson, N.S.B., Oppenheim, A.N., 1977b. Differences in relapse precipitants and coping behaviour between alcohol relapsers and survivors. Behav. Res. Ther. 17, 89-94.

Rohsenow, D.J., Monti, P.M., Rubonis, A.V., Gulliver, S.B., Colby, S.M., Binkoff, J.A., Abrams, D.B., 2001. Cue exposure with coping skills training and communication skills training for alcohol dependence: six and twelve month outcomes. Addiction 96, 1161-1174.

Shiffman, S., 1982. Relapse following smoking cessation: a situational analysis. J. Consult. Clin. Psychol. 50, 71-86.

Skinner, H.A., 1982. Development and Validation of a Lifetime Alcohol Consumption Assessment Procedure. Addiction Research Foundation, Toronto, Substudy No. 1248.
Skinner, H.A., Sheu, W.J., 1982. Reliability of alcohol use indices: the Lifetime Drinking History and the MAST. J. Stud. Alcohol. 43, 1157-1170.

Sobell, L.C., Sobell, M.B., 1986. Can we do without alcohol abusers' self-reports? Behav. Ther. 7, 141-146.

Sobell, L.C., Sobell, M.B., 1995. Alcohol Timeline Followback Users' Manual. Addiction Research Foundation, Toronto, Canada.

Vitaliano, P.P., 1993. Revised Ways of Coping Checklist (RWCCL) and Dimensions of Stress Scale (DSS) Manual. In: University of Washington Seattle.

Vitaliano, P.P., Russo, J., Carr, J.E., Maiuro, R.D., Becker, J., 1985. The Ways of Coping Checklist-Revision and psychometric properties. Multivariate Behav. Res. 20, 3-26.

Zwick, W.R., Velicer, W.F., 1986. Comparison of five rules for determining the number of components to retain. Psychol. Bull. 99, 432-442.

Zywiak, W.H., Connors, G.J., Maisto, S.A., Westerberg, V.S., 1996. Relapse research and the Reasons for Drinking Questionnaire: a factor analysis of Marlatt's relapse taxonomy. Addiction 91, S121-S130. 